\title{
Social interaction and volunteer satisfaction: an exploratory study in primary healthcare
}

\author{
Paola Zappa $\cdot$ Emma Zavarrone
}

Published online: 19 March 2010

(C) Springer-Verlag 2010

\begin{abstract}
This research investigates the relationship between social interaction amongst volunteers working for non-profit organizations and their satisfaction with what they are doing. Drawing on the literature on social capital, we apply social network theories so as to represent various kinds of interaction. We then specify a CATREG model to pick up the effects of goal-specific social capital on volunteer satisfaction. We test our hypotheses on a population of 100 volunteers in a non-profit organization. The empirical evidence we collect reports that benefits of co-working relationships, like the opportunity to acquire competences or the involvement in decision making, affect levels of satisfaction more than any outcomes of solidarity interaction.
\end{abstract}

Keywords Volunteer satisfaction - Social interaction · Social capital · Social network analysis

JEL Classification A14 $\cdot$ C25 $\cdot$ J28 $\cdot$ L31

\section{Introduction}

Over the last few years, the role of the third sector has significantly increased (Borzaga 2002). This seems to be due to reductions in institutional funding, which have brought non-profit organizations to be responsible for services and activities which have traditionally been provided by governments. In this context, the demand for unpaid workers (Dolnicar and Randle 2007) is on the rise. This increase in the

\footnotetext{
P. Zappa $(\bowtie)$

Department of Economics, University of Milano-Bicocca, 20126 Milan, Italy

e-mail: paola.zappa1@unimib.it

P. Zappa · E. Zavarrone

Institute of Behavior, Consumers, Communication, IULM University, 20143 Milan, Italy
} 
importance of volunteer work has thus led to extensive research on the topic. And most attention in the literature has been drawn to the dynamics of attracting and keeping volunteers.

In order to address these issues, several studies have explored the consequences of volunteer work for volunteers themselves. Wilson and Musick (2000) examine its effects on physical and psychological well-being, Meier and Stutzer (2008) on life satisfaction and Wheeler et al. (1998) on self-esteem and happiness. However, most of these scholars have failed to establish clearly the causality between goals being achieved and the choice to start and go on with volunteering. Davis et al. (1999), however, prove that satisfaction with volunteer work itself is the main reason for involvement, both in terms of the amount of time regularly dedicated to it and continuing with it over time. This study claims that satisfaction is influenced mainly by the fulfillment of specific motivations. As monetary compensation is absent, these reasons are seen as the perceived social usefulness of the activity itself and the achievement of non economic rewards. Amongst the latter, the outcomes of social interaction within non-profit organizations have been highlighted as playing a central role, which has, however, not been successfully demonstrated so far.

This article aims at filling the gap between the above theoretical statements and empirical evidence. Hence, it explores the effects on satisfaction of the relational dynamics of volunteering, i.e., relationships with different structures and contents among members of a voluntary organization. The purpose of the study is then twofold: to test whether social interaction is able to influence volunteer satisfaction and identify which benefits are most valued.

The remainder of the article is organized as follows: in Sect. 2, related studies are presented and the framework in which social capital theories are assumed to be an ideal approach for investigating specific aspects of volunteer satisfaction is illustrated. In Sect. 3, the hypotheses being tested are specified and in Sect. 4.1 the methodology adopted is discussed at length. The various approaches to individual social capital and its measurement are elucidated in detail. Section 4.2 describes the survey design and the original data set used, while Sect. 5 points out the most significant results. It shows that in line with the literature, co-working ties are able to variously influence satisfaction with different aspects of volunteer work, while solidarity ties do not significantly promote satisfaction. Finally, Sect. 6 offers the conclusion.

\section{Theoretical framework}

In the literature on non-profit, volunteer satisfaction and its drivers have become a central topic (Hackl et al. 2007; Osborn 2008). Though approaching it from different disciplinary perspectives, most studies state satisfaction depends on the capacity of volunteer work to meet certain individual needs, goals, or motives (see Rubin and Thorelli 1984).

Since volunteering dynamics cannot be explained by traditional labor market theories, these motivations are important. Drawing on Deci (1971), the most general and widespread classification distinguishes between intrinsic and extrinsic reasons 
for offering to do volunteer work. This inventory corresponds to the dichotomy consumption versus investment model (Menchik and Weisbrod 1987). According to the former, volunteering is a utility-bearing activity, which involves contributions of time without coercion or remuneration (Smith 1994, p. 244). Volunteers are seen as being intrinsically motivated when they do not care about possible rewards beyond the activity itself. Intrinsic motivations are thus rooted in the very nature of volunteering. As summarized by Meier and Stutzer (2008), they refer to the three dimensions of: (a) caring about the recipient's utility and then feeling useful to the community by increasing the welfare of others; (b) enjoying the volunteering activity per se (Frey 1997; Deci and Ryan 2000); (c) and enjoying the act of helping others (Andreoni 1990), independently from the consequences of how they are helping.

As for extrinsic motivations, on the contrary, volunteering is an investment good, from which external rewards are expected. They consist in: (a) an improvement of volunteer human capital, i.e., skills and competences useful mainly for finding employment (Müller 1975; Day and Devlin 1998); (b) obtaining social approval and prestige within the reference community; (c) benefiting from investment in individual social networks within or beyond the boundaries of non-profit organizations.

Despite this comprehensive body of literature, the effect of each motivation on volunteer satisfaction is somewhat ambiguous. Some scholars have shown that the decision to start volunteering may be driven by strong intrinsic reasons, but that continuing is more likely to be based on an evaluation of costs and rewards (Tschirhart et al. 2001, p. 424). In doing so, these studies, therefore, imply the supremacy of extrinsic over intrinsic motives in satisfaction formation. In line with these results, there is a recent work by Hackl et al. (2007), where the authors test simultaneously consumption and investment assumptions through an econometric model and find robust empirical evidence for the latter, namely skill acquisition, the deepening of social contacts, and signaling willingness to perform. However, the opposite hypothesis is also supported (Meier and Stutzer 2008).

To sum up, these studies seem to put forward the idea that the process driving volunteer satisfaction is much more complex than traditionally claimed. Moreover, they argue that besides helping others, several other dynamics are involved. Social dynamics amongst members of non-profit organizations have recently drawn great interest (Borzaga and Depedri 2005). ${ }^{1}$ And various motives have been found to be fulfilled by their outcomes. Focussing on social dynamics thus offers an original perspective for approaching volunteer satisfaction. Meier and Stutzer (2008) claim that investing in social networking can be extrinsically or intrinsically rewarding.

\footnotetext{
1 This topic is part of a larger body of recent literature, which has more generally examined the quality of relational life, meaning relationships with family, friends and involvement in associational activities, like non-profit organizations. Some papers have explored and attempted to measure the effects of social interaction on economic behavior and well-being. However, as observed by Stanca (2008, p. 2), these studies on relational capital have frequently "focused on aspects such as trust, social norms,..., whereas relatively little is available about interpersonal relationships". In order to capture the effects of the latter on life satisfaction, Stanca (2008) proposes a measure based on subjective well being. It is assessed by asking the respondents to evaluate their level of life satisfaction.
} 
The nature of the rewards, in fact, depends on whether the volunteers aim at establishing business or similar contacts, useful for enhancing their competences or job opportunities, or just enjoy social interaction without any expectations of future extrinsic rewards. Taking a step further, Degli Antoni (2009) examines the nature of the social networks of volunteers and shows their structure and content can be affected by the importance of a specific motivation. In other words, the author suggests that individuals engage in different relationships so as to satisfy specific motives. Volunteers more interested in fulfilling extrinsic motives devote more effort to building a large network of weak relations, while those intrinsically motivated are more likely to join strong trust relations, based on familiarity. Yeung (2004), Omoto and Snyder (1995) and Hobson et al. (1996) also prove a positive correlation between embeddedness in friendship relationships with other volunteers and satisfaction. Furthermore, Whiteley (1999) and Smith (2000) both analyze social networks with different contents-e.g., co-working, esteem-and demonstrate they provide extrinsic benefits, like skill acquisition or gaining prestige and social recognition. Finally, Borzaga (2002) draws attention to organizational relationships, mainly to direct involvement in decision making. The latter, in fact, is seen as enhancing the level of perceived democraticity of management activities. However, Borzaga's results raise some doubts, since the author does not focus on volunteers, but examines paid and unpaid workers together. According to the abovelisted body of literature, a specific relationship exists between social networks with different content and various rewards: strong relationships (friendship) provide intrinsic rewards, while weak relationships (co-working) extrinsic ones. The importance of these rewards is nonetheless controversial, as different scholars have as yet assigned them different weights.

The effects of social interaction on satisfaction have been more extensively investigated and better formalized in studies on for-profit organizations. A number of articles (Rice and Mitchell 1973; Dean and Brass 1985) on employees' perceptions of their work argue that job satisfaction is positively affected by benefits of social interaction in the work environment. Individual social capital theories, in particular, seem to offer deeper insights. They also provide a useful methodological framework for examining social interaction in voluntary associations, once the differences between them and for-profit organizations have been accounted for. These theories conceive social capital as a resource of individuals and then suggest they take advantage of being embedded in social networks with different structure and content. Flap and Völker (2001) particularly have put forward this goal specificity of social capital. In their model, they distinguish between solidarity (or friendship) and strategic (co-working) relationships among workers employed in the same department. They then conceptualize job satisfaction as a multifaceted dimension, consisting of instrumental aspects like income, security and skills acquisition, and relational ones like general climate and collaboration with peers and superiors. They, therefore, prove the existence of social interaction benefits consistently with those mentioned above. Namely, they find that embeddedness in cohesive solidarity relationships significantly increases the relational aspects of job satisfaction by promoting a better perception of organizational climate, social identity, and feeling part of a group. On the contrary, connectedness to unconnected 
others through strategic ties contributes to new skill acquisition or access to non redundant information and other resources. These benefits, therefore, affect instrumental satisfaction.

\section{Hypotheses}

The present study extends to volunteer satisfaction of the framework Flap and Völker (2001) propose for analyzing the effects of social interaction on job satisfaction. We consider two aspects of volunteer satisfaction-work-related ${ }^{2}$ and relational-and two kinds of relationships_-solidarity and strategic, which we refer to as co-working - among members of a voluntary association. We then assume different configurations of individual social networks correspond to different motivations and, to verify their effects on satisfaction, we posit:

Hypothesis An individual social network with a given structure and content can impact on different aspects of satisfaction with volunteer activity.

According to this hypothesis, the different relationships the volunteers engage in provide them with specific benefits, which depend on their position within the corresponding network. These benefits can variously influence different aspects of satisfaction.

This hypothesis is specified as follows:

$\mathbf{H}_{1}$ The more volunteers are located in an intermediation position within a network of co-working ties which gives access to non redundant information or skill acquisition, the more they are satisfied with the work-related aspects of the activity.

$\mathbf{H}_{2}$ The more volunteers are involved in a network of co-working ties which provides prestige and positive regard by others, the more they are satisfied with the relational aspects of the activity.

$\mathbf{H}_{3}$ The more volunteers are connected in a network of co-working ties to important others which promote involvement in decision making, the more they are satisfied with the relational aspects of the activity.

$\mathbf{H}_{4}$ The more volunteers are involved within a network of solidarity ties which enhances the social climate, the more they are satisfied with the relational aspects of the activity.

Differently from Flap and Vollker, we examine the effect of strategic ties also on prestige and involvement in decision making. Hence, we test the same hypothesis as the authors on work-related satisfaction $\left(\mathrm{H}_{1}\right)$. Moreover, we state that the relational aspects are influenced by centrality in either co-working $\left(\mathrm{H}_{2}\right)$ or solidarity relationships $\left(\mathrm{H}_{4}\right)$ and by connectedness to important other ones $\left(\mathrm{H}_{3}\right)$.

\footnotetext{
${ }^{2}$ In examining satisfaction, we use "work-related" as a synonym of "instrumental".
} 


\section{Research design}

\subsection{Methodology}

In order to investigate the effects of social interaction on volunteer satisfaction, we apply Social Network Analysis (Wasserman and Faust 1994). It allows us to operationalize the above described relational dynamics and examine their effects through appositely defined measures. To be precise, we focus our attention on members of a non-profit organization. We then represent interaction among them as a network, whose nodes are volunteers and ties relations among couples of them (dyads). This network corresponds to an adjacency matrix $\mathbf{A}$ of size $n \times n$, with $n$ the number of nodes. The generic element of $\mathbf{A}, a_{i j}$, represents the tie from node $i$ to node $j(i=1, \ldots, n ; j=1, \ldots, n ; i \neq j)$. We build two networks, one for each relationship. In both of them, we then examine the structure of ties each volunteer is embedded in.

To this purpose we adopt different conceptualizations of individual social capital. Drawing on the classification proposed by Borgatti et al. (1998), we distinguish three approaches:

(1) structural, which represents the structure of ties surrounding the volunteer $i$,

(2) compositional, which looks at the characteristics of the alters to whom $i$ is directly connected,

(3) tie approach, which focuses on i's position in the whole network.

In this work, we consider exclusively direct interaction between each volunteer and the others. Therefore, we select tie and compositional approaches and compute specific network measures for both. In order to examine the network composition, we need to focus on the ego-networks, i.e., the relational network of each volunteer $i$. The tie approach by contrast requires the entire network to be measured in order to be computed.

For each volunteer, the opportunity to have access to volunteering-related information and acquire skills is operationalized as betweenness centrality (Freeman 1979 ) in the co-working network. It is computed as the proportion of times $i$ falls along the shortest path between $j$ and $k\left(g_{j k}\right)$. In formula:

$$
C_{\mathrm{B}}=\frac{\sum_{j<k}^{n} g_{j k}(i)}{g_{j k}}
$$

As betweenness centrality considers the proportion of ego's useful ties, it is a proxy of the possibility to benefit from new knowledge and non redundant information. Operatively, $C_{\mathrm{B}}$ represents ego's intermediate position in the whole network.

The effect of co-working on prestige and positive regard by others is captured by indegree centrality (Freeman 1979) within the corresponding network:

$$
C_{D+i}=\sum_{j=1}^{n} a_{i j}
$$


Indegree centrality represents the number of ties received by ego, weighted for the strength of ties in case of valued relationships. It thus focuses on dyadic interaction among the egos and their alters. $C_{D+i}$ is the most common measure of popularity or prestige. In this context, it stands for the social recognition of commitment volunteers receive from their colleagues.

In order to capture the influence of involvement in decision making, we control for the possible effect of the hierarchical position of alters in the co-working relationship. To this purpose, we compute compositional network measures for co-working ties received, examining the so called in-neighbors of $i$. Namely, we concentrate on the variety in formal position of the in-neighborhood of $i$. It is specified by two distinct measures, which correspond to different organizational structures.

First, we analyse the diversity in hierarchical position between an ego and its alters. This effect is captured by the EI Index:

$$
E I=\frac{E-I}{E+I}
$$

where, given an attribute $c$ (here hierarchical position)

$I \quad$ number of ties $i$ receives from alters with the same value of $c$.

$E$ number of ties $i$ receives from alters with a different value of $c$.

EI ranges from -1 (homophily) to 1(heterophily). Homophily occurs when the proportion of ties sent by volunteers belonging to the same hierarchical level of $i$ is maximal. It is the same for a rigid organization, where volunteers are trusted and asked for advice exclusively by others in the same formal position. By contrast, heterophily corresponds to a difference in hierarchy between an ego and its alters. Hence, it represents the perceived democraticity in decision making mentioned by Borzaga (2002).

Second, we specifically isolate ties sent by volunteers higher in hierarchy. We consider a configuration of the in-neighborhood where $i$ is connected to alters with a higher hierarchical level. The latter, in fact, are expected to provide recognition on individual contribution and involvement. In order to measure this effect, we apply standard indegree centrality, the proportion of in-neighbors of $i$ belonging to a higher formal position. In formula:

$$
{ }_{s} C_{D+i}^{c}=\frac{\sum_{j=1}^{N_{i}} a_{i j}^{c}}{\left(N_{i}-1\right)}
$$

where

$a_{i j}^{c} \quad$ number of ties $i$ receives from alters with a higher level of attribute $c$.

$N_{i}$ in-neighbors of $i$, i.e., number of ties received by $i$.

At last, involvement into the solidarity relation is captured, as for co-working, by indegree centrality within the solidarity network. In doing so, we consider the number of volunteers who have built a solidarity relationship with the ego. 
Following previous studies, we also control for the effects of individual attributes, i.e., socio-demographic and activity-related characteristics. As sociodemographic attributes, we select education (Kulik 2007), gender (Frey 1997), and age (Borzaga and Tortia 2006), while activity-related characteristics correspond to the formal or hierarchical position (Liao-Troth and Dunn 1999), task performed, and seniority (Flap and Völker 2001). ${ }^{3}$

Analyses on the influence of social capital on satisfaction are carried out using a regression model. Instead of the traditional OLS regression, we apply an alternative which has been recently developed for examining categorical data, i.e., CATREGCategorical Regression with optimal scaling-(Van der Kooij and Meulman 1997). It differs from the OLS regression in the estimation method, while its regression equation presents the standard formula. CATREG was introduced to investigate non linear relations and has been successfully used in several fields of research. To our knowledge, it has never been applied to social capital studies. As stated in Van der Kooij et al. (2006, p. 448), the CATREG model fits the classical linear regression model with nonlinear transformations of the variables, written as:

$$
\varphi_{r}(\mathbf{y})=\sum_{j=1}^{J} \beta_{j} \varphi_{j}\left(\mathbf{x}_{j}\right)+\mathbf{e}
$$

with loss function

$$
L\left(\varphi_{r} ; \varphi_{1}, \ldots, \varphi_{j} ; \beta_{1}, \ldots, \beta_{j}\right)=N^{-1}\left\|\varphi_{r}(\mathbf{y})-\sum_{j=1}^{J} \beta_{j} \varphi_{j}\left(\mathbf{x}_{j}\right)\right\|^{2}
$$

with $N$ the number of observations, $J$ the number of predictor variables, $\beta_{j}$ the regression coefficients, $\varphi_{r}(\mathbf{y})$ the transformation for the response variable $\mathbf{y}, \varphi_{j}\left(\mathbf{x}_{j}\right)$ the transformations for predictor variables $\mathbf{x}_{j}$ and $\mathbf{e}$ the error vector, and where $\|.\|^{2}$ denotes the squared Euclidean norm. The loss function is minimized over $\beta_{j}, \varphi_{j}\left(\mathbf{x}_{j}\right)$ and $\varphi_{r}(\mathbf{y})$ to maximize the least square fit between $\varphi_{r}(\mathbf{y})$ and the linear combination $\sum_{j=1}^{J} \beta_{j} \varphi_{j}\left(\mathbf{x}_{j}\right)$. Since the transformed variables $\varphi_{r}(\mathbf{y})$ and $\varphi_{j}\left(\mathbf{x}_{j}\right)$ are centered and normalized to have sum of squares equal to $N$, the loss function maximizes the (squared) multiple correlation.

This procedure introduces a transformation that quantifies categorical variables (of ordinal-nominal scale) by assigning numerical scores to their levels (including applying non-linear transformations-e.g., splines with two or more degrees and two or more knots) to produce an optimal linear regression equation for the transformed variables. Operationally, the algorithm minimizes a least squares function using alternating least squares to find optimal quantifications for categorical variables, while simultaneously optimizing the squared multiple regression coefficient. The combination in our study of a small sample with a large number of variables and of values for variables-i.e., numerical predictors, dummies, and categorical predictors-would prevent the exploitation of OLS

\footnotetext{
${ }^{3}$ Seniority is the number of years since the volunteer joined the organization and stands for the time spent building social relationships.
} 
regression. Being strongly suggested when models and data sets are affected by this sort of problem, CATREG seems thus to be the optimal solution here.

\subsection{Data}

We tested the hypotheses on a non-profit organization providing primary healthcare to a small urban community of approximately 30,000 residents in Northern Italy. Besides 15 paid workers, who were excluded from this research, around 100 volunteers are employed. They are organized in teams of almost the same number, each managed by a supervisor, and their activities are scheduled in shifts covering week evenings and nights and $24 \mathrm{~h}$ a day at weekends. Some volunteers also have management, fund raising, or training tasks. Since they are expected to deal with critical patients, they are required to attend training courses to acquire specific skills and pass an exam before entering the organization.

We created an ad hoc roster questionnaire exploring different aspects of satisfaction with volunteering (the dependent variable), co-working and solidarity relationships among volunteers and individual and volunteering activity-related characteristics (the independent variables).

\subsubsection{Dependent variable}

We specified the dimensions of satisfaction according to the prevailing literature. Namely, we replicated the detailed model proposed by Borzaga and Depedri (2005) and Borzaga and Tortia (2006) for classifying the mix of economic, extrinsic, relational, process related, and other incentives the organization provides to match members' motivations. As the original questionnaire was administered to non-profit workers, we adapted it to volunteers, drawing on the Red Cross questionnaire on volunteer satisfaction. Thus, we removed items on the economic aspects of the activity, including an item on involvement in decision making and distinguished relationships with other volunteers into three items. They regard formal (recognition of an individual contribution), informal (solidarity relation), and hierarchical (relations with superiors) ties.

In detail, satisfaction was then specified by the following eight items: opportunity to help others, volunteer hours, volunteer security, volunteer variety, involvement in decision making, recognition of an individual contribution, solidarity relations with other volunteers, and relations with superiors. They were measured on a four-point interval Likert-type scale, ranging from 1 (not at all) to 4 (to a great extent).

\subsubsection{Independent variables}

The main predictors of our regression model are the social capital measures on interaction amongst volunteers described in Sect. 4.1. They are derived from relational data. In order to collect them, we investigated solidarity and co-working relationships with name-generating questions. Respondents were provided with a list of all the volunteers' names and codes. Then, to respect privacy, they were asked to report on the questionnaire the codes of those they were connected to by 
solidarity or co-working ties. Furthermore, to limit measurement errors on the relational section, they were not restricted to a fixed number of nominations.

Following Flap and Vollker (2001), the co-working relationship was operationalized as professional trust. It was observed by asking the question: "Which volunteers do you regard as competent?". In this way, we hypothesized that competent volunteers are those which others seek out for advice and choose as discussion partners on performing the activity. Therefore, they can provide others with useful knowledge on the activity-related aspects of volunteering. At the same time, they are also particularly well regarded for their competence, their opinions are highly valued and they are likely to be involved in the decision-making process.

Drawing on the literature on informal relationships in work or similar to work environments (Krackhardt 1992; Krackhardt and Hanson 1993), we captured solidarity ties as friendship. They were measured on a three-point ordinal scale ( $1=$ empathy; $2=$ spending spare time together; $3=$ being close friends $)$ so as to disentangle the effects of weak and strong ties.

For each relationship, we built an adjacency matrix $\mathbf{A}$, whose rows and columns are labeled with volunteer codes. For professional trust, the generic value in the intersection cell $a_{i j}$ equals 1 if there is a tie from volunteer $i$ to volunteer $j$ and 0 otherwise. For friendship, $a_{i j}$ assumes values ranging from 1 to 3 depending on the strength of tie from $i$ to $j$, while equals 0 if there is no tie. Since the relationships can be not reciprocated, both matrices are asymmetric.

As illustrated above, we considered individual variables. Age was dichotomized as "young", from 18 to 35 years and "adult", from 36 to 65, to reduce the number of values for variable. Education was distinguished into five levels, from primary school to post-degree. Finally, we also included gender. In respect to activity-related attributes, seniority was measured as the number of years since the volunteer joined the organization. The task performed was captured as the degree of involvement in extra-activities like management and training (measured on a four-point ordinal scale, where $1=$ never; ...; 4 = always). The formal position entered the model as a dummy, so as to distinguish supervisors from the others.

\section{Results}

\subsection{Descriptive individual and network statistics}

The questionnaire, appositely pre tested, ${ }^{4}$ was self administered to volunteers in October-November 2007. It was returned by 64 volunteers; since $12.50 \%$ of them did not fill in the relational part, the analyses were restricted to 56 individuals. We then checked for socio-demographic characteristics and verified the self-selected sample was statistically representative of the population investigated.

The sample consisted of $59 \%$ males and $41 \%$ females with a high school (50\%) or middle school $(26.80 \%)$ education. The majority $(66.10 \%)$ were young (aged from 18 to 35$)$. The percentage of graduates or university students tended to

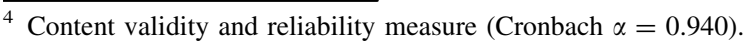


Table 1 Descriptive statistics on the single aspects of volunteer satisfaction $(n=56)$

\begin{tabular}{llr}
\hline & Mean (Std. dev.) & c.v. \\
\hline$I_{1}$ Opportunity to help others & $3.480(.630)$ & .180 \\
$I_{2}$ Volunteering hours & $2.860(.820)$ & .290 \\
$I_{3}$ Volunteering security & $3.110(.680)$ & .220 \\
$I_{4}$ Volunteering variety & $2.910(.690)$ & .240 \\
$I_{5}$ Involvement in decision making & $2.040(.910)$ & .450 \\
$I_{6}$ Recognition of one's contribution & $2.480(1.040)$ & .420 \\
$I_{7}$ Solidarity relations with other volunteers & $2.960(.930)$ & .310 \\
$I_{8}$ Relations with superiors & $2.230(.890)$ & .400 \\
\hline
\end{tabular}

increase only amongst the young, who were mainly medical students. Seniority in the organization was high, since respondents had been volunteers for an average 7.60 years. Furthermore, $20 \%$ were supervisors, while only $15 \%$ took part in management or similar activities.

In respect to network structure, we observed both the networks were somewhat sparse. In fact, just a small proportion of all the possible ties was active (density ${ }^{5}$ $26 \%$ for solidarity and $21 \%$ for co-working, respectively). The two relationships differed in the degree of tie reciprocity: within the solidarity network $47 \%$ of ties was reciprocated, while in co-working the proportion dropped to only $24 \%$.

We then went onto examine satisfaction. Statistics for each item are displayed in Table 1. It shows volunteers were on average fairly satisfied with their activities. However, a deeper investigation into specific aspects of satisfaction revealed the members of the organization were mostly satisfied with the opportunity to help others and with solidarity relationships. By contrast, co-working dynamics were overall perceived as problematic. It is pointed out by the scores of involvement in decision making, relationships with superiors and recognition, which examine professional regard either by peers or superiors. Furthermore, these aspects are affected by the highest degree of variability. ${ }^{6}$ Finally, the tangible characteristics of volunteering, like time devoted to it or its variety and security, were in general moderately appreciated.

Through exploratory factor analysis, the eight items on satisfaction were then reduced to two dimensions. ${ }^{7}$ Consistently with Flap and Völker's (2001) findings, they correspond to relational $\left(I_{5}-I_{8}\right)$ and work-related satisfaction $\left(I_{1}-I_{4}\right)$. The

\footnotetext{
5 In its most simple formula, density represents the proportion of all possible ties that are actually present in the network. For a directed network it is computed as (Wasserman and Faust 1994):

where $m=$ number of ties

$$
D=\frac{m}{n(n-1)}
$$

$n=$ number of nodes

$0 \leq D \leq 1$.

6 The coefficient of variation (c.v.) is respectively 0.450 for involvement in decision making, 0.420 for recognition and 0.400 for relations with superiors.

${ }^{7} \mathrm{KMO}=0.74$; Bartlett's sphericity test $=141.43 * * *$.
} 
former represents satisfaction with benefits of embeddedness within the non-profit organization, meaning relationships of different content, solidarity or co-working, and with different individuals, peers or superiors. The latter considers intrinsic aspects of volunteering, like its social usefulness, and characteristics strictly related to the activity itself. The two dimensions together explain $58.56 \%$ of the total variance; in detail, relational satisfaction accounts for $44.16 \%$ and work-related satisfaction for $14.40 \%$ of the variability in the original eight variables. Scores of each dimension were then computed as the simple mean of the related items fourpoint Likert scale scores. They were used as dependent variables in the regression equations.

\subsection{Social capital effect model}

In the first place, we computed the social capital measures mentioned in Sect. 4.1, and then verified the existence of association/correlation between individual covariates and scores on satisfaction dimensions. We computed in detail Pearson's correlation coefficient for quantitative (Table 2) and contingency coefficient for categorical variables. Individual characteristics like gender, age, and education resulted independent from work related $\left(S_{\mathrm{w}}\right)$ and relational satisfaction $\left(S_{\mathrm{R}}\right)$, and were then ruled out from further analysis. However, a significant relation amongst satisfaction and seniority in the organization $\left(\rho=0.323, p<0.05\right.$ for $\left.S_{\mathrm{R}}\right)$ and task performed $\left(C=0.460, p<0.01\right.$ for $S_{\mathrm{w}}$ and $0.507, p<0.01$ for $S_{\mathrm{R}}$ ) was found.

Table 2 Pearson's correlation matrix

\begin{tabular}{|c|c|c|c|c|c|c|c|}
\hline & $\begin{array}{l}\text { Work- } \\
\text { related } \\
\text { satisfaction }\end{array}$ & $\begin{array}{l}\text { Relational } \\
\text { satisfaction }\end{array}$ & $\begin{array}{l}C_{\mathrm{B}} \\
\text { co-working }\end{array}$ & $\begin{array}{l}C_{D+i} \\
\text { co-working }\end{array}$ & $\begin{array}{l}C_{D}+i \\
\text { solidarity }\end{array}$ & $\begin{array}{l}{ }_{s} C_{D+i}^{c} \\
\text { co-working } \\
\text { higher } \\
\text { hier. level. }\end{array}$ & $\begin{array}{l}\text { EI Index } \\
\text { co-working } \\
\text { hier. }\end{array}$ \\
\hline$S_{\mathrm{w}}$ & 1.000 & & & & & & \\
\hline$S_{\mathrm{R}}$ & $.512 * *$ & 1.000 & & & & & \\
\hline $\begin{array}{l}C_{\mathrm{B}} \\
\text { co-working }\end{array}$ & $.108 *$ & -.102 & 1.000 & & & & \\
\hline $\begin{array}{l}C_{D}+i \\
\text { co-working }\end{array}$ & $-.205^{*}$ & $.178^{*}$ & .011 & 1.000 & & & \\
\hline $\begin{array}{l}C_{D}+i \\
\text { solidarity }\end{array}$ & -.195 & .085 & $-.019 * *$ & $.689 * *$ & 1.000 & & \\
\hline $\begin{array}{c}{ }_{s} C_{D+i}^{c} \text { co- } \\
\text { working } \\
\text { higher } \\
\text { hier. level. }\end{array}$ & $.248^{*}$ & $.312^{* * *}$ & .010 & $-.699 * *$ & $-.677 * *$ & 1.000 & \\
\hline $\begin{array}{l}\text { EI Index co- } \\
\text { working } \\
\text { hier. }\end{array}$ & $.247 *$ & .093 & -.200 & .053 & .024 & .138 & 1.000 \\
\hline
\end{tabular}

$* * * p<0.001, * * p<0.01, * p<0.05,2$-tailed tests. $(n=56)$ 
Table 3 Effects of individual covariates on volunteer satisfaction

\begin{tabular}{llc}
\hline Baseline model & & \\
\hline Variables & $S_{\mathrm{w}}$ & $S_{\mathrm{R}}$ \\
& $\beta_{\mathrm{W}}$ & $\beta_{\mathrm{R}}$ \\
\hline Hierarchical level & $-.480^{* * *}$ & -.040 \\
Seniority & -.200 & $.390^{* * *}$ \\
Task & $.360^{* *}$ & $.470^{* * *}$ \\
$R^{2}$ & .330 & .540 \\
\hline
\end{tabular}

*** $p<0.001, * * p<0.01, * p<0.05,2$-tailed tests. $(n=56)$

Finally, we observed a strong and highly significant correlation amongst the two dimensions of satisfaction $(\rho=0.512, p<0.01)$.

We then ran the regression models. Analyses were carried out in two steps using CATREG. First, before testing the effects on satisfaction of an individual position in the network of either co-working or solidarity relations, we checked for the dependence of satisfaction on individual covariates. This constitutes the Baseline Model, since it conceives satisfaction as affected exclusively by the characteristics of individual volunteering, in terms of participation to the activity. This model served as a benchmark against which to compare the effects of social interaction. Table 3 reports relating results. $S_{\mathrm{w}}$ appears positively affected by the degree of involvement in extra tasks performed and especially by the hierarchical position ${ }^{8}$ $\left(R^{2}=0.330\right) . S_{\mathrm{R}}$ is explained by the positive influence of either task or seniority $\left(R^{2}=0.540\right)$. These findings suggest that the more active the role volunteers play in the organization management, the more satisfied they are with volunteering itself.

Second, we added individual social capital measures. In order to verify whether they influence the expected dimension of satisfaction, we tested the effect of each measure on both. As displayed in Table 4, the outcomes of social interaction significantly contribute to either $S_{\mathrm{w}}\left(R^{2}\right.$ increases from 0.330 to 0.610$)$ or $S_{\mathrm{R}}\left(R^{2}\right.$ from 0.540 to 0.670 ).

In respect to $S_{\mathrm{w}}$, we found support for the hypothesis $\mathrm{H}_{1}$. As the value of $\beta_{\mathrm{w}}$ for $C_{\mathrm{B}}$ points out, $S_{\mathrm{w}}$ is promoted by having access to information and knowledge by means of co-working. This knowledge is particularly valued as it helps improve the quality of volunteering and develop job-related skills. The effect of this kind of social interaction is nonetheless moderately significant $(0.01<p<0.05)$. Interestingly enough, $S_{\mathrm{w}}$ is also explained by the strong negative contribution of indegree centrality $\left(C_{D+i}\right)$ in co-working. However, this effect is diminished by the positive coefficient for EI Index. A positive value of $\beta_{\mathrm{w}}$ corresponds to heterophily and implies that the less homophily in formal positions, the more satisfaction. In other words, $S_{\mathrm{w}}$ is increased by being regarded as competent, involved in decision making and asked for advice, by volunteers placed in a different hierarchical position, either

\footnotetext{
$\overline{{ }^{8} \text { Hierarchical level is coded as } 1}=$ supervisor, 2 = volunteer. As we assume "volunteer" as reference category, the negative $\beta_{\mathrm{w}}$ coefficient indicates that the higher the formal position the greater work-related satisfaction.
} 
Table 4 Effects of individual and network covariates on volunteer satisfaction

\begin{tabular}{lcc}
\hline Social capital model & & \\
\hline Variables & $S_{\mathrm{w}}$ & $S_{\mathrm{R}}$ \\
& $\beta_{\mathrm{W}}$ & $\beta_{\mathrm{R}}$ \\
\hline Hierarchical level & $-.500^{* * *}$ & -.090 \\
Seniority & -.100 & .240 \\
Task & $.590^{* * *}$ & $.550^{* * *}$ \\
$C_{\mathrm{B}}$ co-working & $.230^{*}$ & .060 \\
$C_{D}+i$ co-working & $-.47^{* * *}$ & $.420^{* * *}$ \\
$C_{D}+i$ solidarity & .200 & .130 \\
${ }_{s} C_{D}^{c}+i$ co-working higher hier. level & .150 & $.55^{* * *}$ \\
$E I$ Index co-working hierarchy & $.300^{* * *}$ & .010 \\
$R^{2}$ & .610 & .670 \\
\hline$* * * p<0.001, * * p<0.01, * p<0.05$, 2-tailed tests. $(n=56)$ &
\end{tabular}

higher up or lower down. By contrast, the number of ties received does not seem to play any role. The co-working relationship exerts an even more important influence on $S_{\mathrm{R}}$. In fact, the positive and highly significant coefficient for $C_{D+i}$ points out that $S_{\mathrm{R}}$ is affected by the number of ties received $\left(\mathrm{H}_{2}\right)$. It stands for positive regard by others and recognition of individual contribution. Indeed, the value of $\beta_{\mathrm{w}}$ for standard indegree centrality referred to ties with higher hierarchical level volunteers $\left({ }_{s} C_{D}^{c}+i\right)$ draws attention to the content of these ties, in terms of the proportion sent by supervisors. This seems to indicate the importance of interacting with the board/management staff and, then, of feeling a valuable member of the organization (as posited by $\mathrm{H}_{3}$ ). The coefficient for the solidarity relationship $\left(C_{D}+i\right)$ is, on the contrary, not significant $(p>0.05)$. It is then rejected the hypothesis $\mathrm{H}_{4}$, which sustains that building friendship ties can influence volunteer $S_{\mathrm{R}}$ positively.

\section{Discussion and conclusions}

In this work, we tested the influence of social interaction within voluntary organizations on the satisfaction of their members. In order to formalize the dynamics described in the related literature, we adopted a conceptual framework proposed for exploring job satisfaction, having dealt with the differences between for-profit and non-profit work environment and workers and volunteers. We then examined the effects of social relationships on a sample of individuals volunteering in primary healthcare.

First, we verified that volunteer satisfaction is a complex concept, consisting of two dimensions, i.e., work related $\left(S_{\mathrm{w}}\right)$ and relational satisfaction $\left(S_{\mathrm{R}}\right)$. $S_{\mathrm{w}}$ confirms the interest of volunteers in the activity itself, in terms of either tangible characteristics or advantages for the community. The importance of intrinsic 
motivations and their fulfillment is thus supported. At the same time, it is pointed out that when evaluating their experience in voluntary associations, individuals take into account its relational aspects as well. These aspects resulted furthermore the most critical and negatively valued in this study.

Taking a step further, we explored the influence on satisfaction dimensions of different outcomes of social relationships within the organization. We provided evidence that the latter play a central role. Moreover, we showed that the dynamics of social interaction are more various and counterintuitive than highlighted in past research. As CATREG Social Capital Model revealed, volunteers evaluate either the quantity or the quality of ties built with their peers. Therefore, only some kinds of relationships, with very specific content, structure, and benefits, have an effect on their level of satisfaction. With reference to the content, we pointed out that coworking ties, weak by definition, are more able to affect satisfaction than solidarity ones. The main finding in this respect is that volunteers are especially satisfied by the opportunity to be really involved in their organization, by means of connectedness to other more important volunteers. The positive social climate often cited in the literature is seen to derive more from co-working interaction than from embeddedness in purely informal or friendship relationships. This particular aspect of social networking has been proven to influence either $S_{\mathrm{w}}$ or $S_{\mathrm{R}}$. With regard to the former, we in fact observed the significant contribution of involvement in decision making and prestige: the positive coefficient of EI Index seems to stress the need for the perceived sense of democraticity claimed by Borzaga (2002). It can be ensured by a flat organization, where hierarchies are not formalized and coworking ties exist amongst members in different formal positions. This result is fostered by those on $S_{\mathrm{R}}$. In fact, it was found to be promoted by being considered competent and then, presumably, asked for advice by either a number of others (hypothesis $\mathrm{H}_{2}$ confirmed), or especially by volunteers in charge of managing the organization. The positive coefficient of this latter effect, together with betweenness centrality in co-working, furthermore proves the interest in individual benefits of volunteering. Similarly to Hackl et al. (2007), this finding emphasizes the strength of the investment model and, consequently, of the importance of extrinsic motivations to volunteering. The interest in gaining recognition indicates individuals perceive volunteering as a way to affirm themselves and their own capabilities. The importance of skill acquisition, although rather moderate in magnitude and poorly significant, points to an instrumental component in volunteer work.

Within the framework illustrated here, some findings call for more attention, further refinements and a deeper investigation into the corresponding dynamics. The scarce significance of the solidarity relationship, whose importance on volunteer enrollment and on the decision to continue volunteering has been widely claimed (Yeung 2004), suggests friendship ties could exert their influence on a different dimension from satisfaction. In this sense, effects of solidarity and feeling of emotional support on volunteer happiness and well being could be examined. Likewise, other forms of social interaction could be explored. Mainly, the general co-working relation, which here-following Flap and Völker (2001)-has been made operative as professional trust, could be more precisely specified. Advice seeking and involvement in decision making, for example, which we have inferred 
as a consequence of "regarding as competent" and "considering professionally trustworthy", could be made explicit or other strategic relationships could be investigated. Finally, it is wiser to conceive this research just as a case study. As a consequence, attempts to extend the model from the very specific kind of volunteering examined in this paper to others should be made. In doing so, the greatest limitation of this work, i.e., the focus on a volunteering activity whose dayby-day dynamics strongly resemble those of a traditional work context, could be removed.

\section{References}

Andreoni J (1990) Impure altruism and donations to public goods: a theory of warm-glow giving. Econ J 100(401):464-477

Borgatti SP, Jones C, Everett MG (1998) Network measures of social capital. Connections 21(2):27-36

Borzaga C (2002) Sull'impresa sociale. Working Paper 19. ISSAN University of Trento

Borzaga C, Depedri S (2005) Interpersonal relations and job satisfaction: some empirical results in social and community care services. In: Gui B, Sudgen R (eds) Economics and social interaction. Accounting for interpersonal relations. Cambridge University Press, Cambridge, UK

Borzaga C, Tortia E (2006) Worker motivations, job satisfaction, and loyalty in public and non profit social services. Nonprofit Volunt Sect Q 35:225-248

Davis MH, Mitchell KV, Hall JA, Lothert J, Snapp T, Meyer M (1999) Empathy, expectations, and situational preferences: personality influences on the decision to participate in volunteer helping behaviors. J Pers 67:469-503

Day K, Devlin RA (1998) The payoff to work without pay: volunteer work as an investment in human capital. Can J Econ 31(5):1179-1191

Dean JW, Brass DJ (1985) Social interaction and the perception of job characteristics in an organization. Hum Relat 38:571-582

Deci EL (1971) Effects of externally mediated rewards on intrinsic motivation. J Pers Soc Psychol 18:105-115

Deci EL, Ryan RM (2000) Intrinsic and extrinsic motivations: classic definitions and new directions. Contemp Educ Psychol 25:54-67

Degli Antoni G (2009) Intrinsic vs. extrinsic motivations to volunteer and social capital formation. Kyklos 62(3):359-370

Dolnicar S, Randle M (2007) What moves which volunteers to donate their time? An investigation of psychographical heterogeneity among volunteers in Australia. Voluntas (Int J Volunt Nonprofit Organ) 18(2):135-155

Flap H, Völker B (2001) Goal specific social capital and job satisfaction: effects of different types of networks on instrumental and social aspects of work. Soc Netw 23:297-320

Freeman LC (1979) Centrality in social networks: conceptual clarification. Soc Netw 1:215-239

Frey BS (1997) Not just for the money. An economic theory of personal motivation. Edward Elgar, Cheltenham, UK and Brookfield, USA

Hackl F, Halla M, Pruckner GJ (2007) Volunteering and income-The fallacy of the good Samaritan? Kyklos 60(1):77-104

Hobson CJ, Rominger A, Malec K, Hobson CL, Evans K (1996) Volunteer-friendliness of nonprofit agencies: definition, conceptual model and applications. J Nonprofit Public Sect Mark 4(4):27-42

Krackhardt D (1992) The strength of strong ties: the importance of Philos in organizations. In: Nohria N, Eccles RC (eds) Networks and organizations: structure, form and action. Harvard Business School Press, Boston, pp 216-239

Krackhardt D, Hanson JR (1993) Informal networks: the company behind the chart. Harvard Bus Rev 71:104-111

Kulik L (2007) Explaining responses to volunteering: an ecological model. Nonprofit Volunt Sect Q 36:239-255 
Liao-Troth MA, Dunn CP (1999) Social constructs and human service: managerial sensemaking of volunteer motivation. Voluntas (Int J Volunt Nonprofit Organ) 10(4):345-361

Meier S, Stutzer A (2008) Is volunteering rewarding in itself? Econ 75:39-59

Menchik P, Weisbrod B (1987) Voluntary labor supply. J Public Econ 3:159-183

Müller MW (1975) Economic determinants of volunteer work by women. J Women Cult Soc 1:325-335

Omoto AM, Snyder M (1995) Sustained helping without obligation: motivation, longevity of service, and perceived attitude change among AIDS volunteers. J Pers Soc Psychol 68(4):671-686

Osborn J (2008) Volunteer Satisfaction and dissatisfaction: the impact of attrition. Aust J Volunt 13(1):84-87

Rice LE, Mitchell TR (1973) Structural determinants of individual behavior in organizations. Adm Sci Q 18:56-70

Rubin A, Thorelli IM (1984) Egoistic motives and longevity of participation. J Appl Behav Sci 23(3):223-235

Smith DH (1994) Determinants of voluntary association participation and volunteering: a literature review. Nonprofit Volunt Sect Q 23(3):243-263

Smith DH (2000) Grassroots associations. Sage, Thousand Oaks, CA

Stanca L (2008) With or without you? Measuring the quality of relational life throughout the world. Working Paper 144. Department of Economics, University of Milano-Bicocca

Tschirhart M, Mesch DJ, Perry JL, Miller TK, Lee G (2001) Stipended volunteers: their goals, experiences, satisfaction, and likelihood of future service. Nonprofit Volunt Sect Q 30(3):422-443

Van der Kooij AJ, Meulman JJ (1997) MURALS: Multiple regression and optimal scaling using alternative least squares. In: Bandilla W, Faulbaum F (eds) Advances in statistical software 6. Lucius \& Lucius, Stuttgart, pp 99-106

Van der Kooij AJ, Meulman JJ, Heiser WJ (2006) Local minima in categorical multiple regression. Comput Stat Data Anal 50(2):446-462

Wasserman S, Faust K (1994) Social network analysis: methods and applications. Cambridge University Press, Cambridge

Wheeler JA, Gorey KM, Greenblatt B (1998) The beneficial effects of volunteering for older volunteers and the people they serve: a meta-analysis. Int J Aging Hum Dev 47(1):69-79

Whiteley PF (1999) The origins of social capital. In: Van Deth JW (ed) Social capital and European democracy. Routledge, New York, pp 25-44

Wilson J, Musick MA (2000) Who cares? Toward an integrated theory of volunteer work. Am Sociol Rev 62:694-713

Yeung AB (2004) An intricate triangle-Religiosity, volunteering, and social capital: the European perspective, the case of Finland. Nonprofit Volunt Sect Q 33(3):401-422 